\title{
Preparation and Properties of Mesoporous Carbon Composite as Negative Electrode Materials
}

\author{
Zhengping Zhao ${ }^{1,2}$, Sitao Shen ${ }^{2}$, Feng Chen ${ }^{2}$, Mingqiang Zhong ${ }^{2}$ and Jia Wei Chew ${ }^{3, *}$ \\ ${ }^{1}$ Zhijiang College, Zhejiang University of Technology, Hangzhou 310014, China \\ ${ }^{2}$ College of Materials Science and Engineering, Zhejiang University of Technology, Hangzhou \\ 310014, China \\ ${ }^{3}$ School of Chemical and Biomedical Engineering, Nanyang Technological University, 637459, \\ Singapore \\ *E-mail:xxsimen@163.com
}

doi: $10.20964 / 2019.11 .08$

Received: 5 June 2019 / Accepted: 6 August 2019 / Published: 7 October 2019

\begin{abstract}
Using sodium lignosulfonate as carbon source, microspheres were prepared by ultrasound. Molybdenum disulfide was synthesized directly by hydrothermal method and grown on the surface of lignin microspheres. Then, molybdenum disulfide modified porous microsphere carbon material was prepared by pyrolysis at high temperature and used as the cathode material of lithium ion battery to study its electrochemical properties. The size of lignin microspheres was about $500 \mathrm{~nm}$. The spacing of the molybdenum disulfide coating on the surface was $0.52 \mathrm{~nm}$. After sintering, the diameter of microspheres is about $300 \mathrm{~nm}$ and the surface aperture of $\mathrm{MoS}_{2} @ \mathrm{C}$ microspheres is about $300 \mathrm{~nm}$. The initial chargedischarge specific capacity was $1049 \mathrm{mAh} / \mathrm{g}$, and the retention rate of 200 charge-discharge specific capacity was $87.3 \%$. The scanning rate of cyclic voltammetric curves show that the electrical properties of $\mathrm{MoS}_{2} @ \mathrm{C}$ microspheres are stability.
\end{abstract}

Keywords: Lignin, $\mathrm{MoS}_{2} @ \mathrm{C}$ microspheres, Hydrothermal method, Electrochemical properties

\section{FULL TEXT}

(C) 2019 The Authors. Published by ESG (www.electrochemsci.org). This article is an open access article distributed under the terms and conditions of the Creative Commons Attribution license (http://creativecommons.org/licenses/by/4.0/). 